\title{
Identidad, características
}

y desarrollo social,

económico y político de las cooperativas costarricenses. Atisbos en el sector de economía social

Identity, characteristics and social, economic and political development of the Costa Rican cooperatives. Glimpses in the social economy sector.

Identidade, características e desenvolvimento social, econômico e político das cooperativas costa-riquenhas. Vislumbres no setor de economia social

\section{Ligia Roxana Sánchez Boza*}

Recibido: 20 de septiembre de 2018

Aceptado: 14 de enero de 2019

Publicado: 5 de abril de 2019

Cómo citar este artículo:

Sánchez Boza, L.R. (2019). Identidad, características y desarrollo social, económico y político de las cooperativas costarricenses. Atisbos en el sector de economía social.

Cooperativismo \& Desarrollo, 27(1), 1-27. doi: https://doi.org/10.16925/2382-4220.2019.01.02

Artículo de reflexión. https://doi.org/10.16925/2382-4220.2019.01.02

* Universidad de Costa Rica. San José. Costa Rica.

Correo electrónico: metanoia@abogados.or.cr 


\section{Resumen}

A partir del desarrollo de las cooperativas, en el siglo xx se hace referencia a los aspectos más importantes de la vida del cooperativismo costarricense, con base en la legislación promulgada, y tomando algunos datos ofrecidos por autores interesados en este tipo de desarrollo socio empresarial. Se resalta la expansión política del cooperativismo costarricense en el ámbito nacional y se atrae la atención en la ausencia de reconocimiento de sectores que como ahorro y crédito y las mujeres cooperativistas dentro de la organización política del Consejo Nacional de Cooperativas. A más de un siglo, el Índice de Progreso Social ofrece datos importantes sobre el impacto social del cooperativismo, en algunos de los cantones que demuestra su vigencia e importancia para la economía del país. La influencia de entes como la Alianza Cooperativa Internacional, el avance de los derechos equitativos de las mujeres y la aceptación de normas internacionales de contabilidad han influido en la propuesta de proyectos, algunos con éxito, otros están a la espera de la decisión legislativa, como es la incorporación de un sector de economía social.

Palabras clave: cooperativismo costarricense, integración, cooperativa interna y externa, contabilidad, gobierno corporativo.

\section{Summary}

Starting from the development of cooperatives in the twentieth century, this paper refers to the most important aspects of the life of the Costa Rican cooperatives, based on the legislation enacted, and taking some data offered by authors interested in this type of social entrepreneurship development. This paper highlights the political expansion of cooperativism in Costa Rican and attracts attention in the lack of recognition of the importance of the cooperatives in certain sectors such as savings and credit, and also of lack of recognition that women cooperative members suffer within the political organization of the National Council of Cooperatives. More than a century later, the Social Progress Imperative index (SPI) provides important data on the social impact of cooperativism in some of the country cantons, which proves the great importance of cooperativism in the national economy. The influence of entities such as the International Cooperative Alliance, the Advancement of Women's equitable rights and the acceptance of international accounting standards, have generate important projects promoting gender equity, and better controls of national cooperatives, some of them successful, others are waiting for the legislative approval, such as the creation of a social economic sector, where cooperatives might have a vital role.

Key words: Costa Rican cooperativism, integration, internal and external cooperative, Accounting, corporate governance.

\section{Resumo}

A partir do desenvolvimento das cooperativas no século $\mathrm{xx}$, faz-se referência aos aspectos mais importantes da vida do cooperativismo costa-riquenho com base na legislação promulgada e ao tomar alguns dados oferecidos por autores interessados nesse tipo de desenvolvimento socio-empresarial. Ressalta-se a expansão política do cooperativismo costa-riquenho no âmbito nacional e atrai-se a atenção para a ausência de reconhecimento de setores que como poupança e crédito e as mulheres cooperativistas dentro da organização política do Conselho Nacional de cooperativas. Há mais de um século, o Índice de Progresso Social oferece dados importantes sobre o impacto social do cooperativismo em alguns dos cantões que demonstram sua vigência e importância para a economia do país. A influência de entes, como a Aliança Cooperativa Internacional, o avanço dos direitos equitativos das mulheres e a aceitação de normas internacionais de contabilidade afetaram a proposição de projetos, alguns bem-sucedidos e outros que aguardam a decisão legislativa, como é a incorporação de um setor de economia social.

Palavras-chave: cooperativismo costa-riquenho, integração, cooperativa interna e externa, contabilidade, 


\section{Introducción}

El cooperativismo costarricense cumplió más de un siglo, muchos han sido sus logros y poco a poco se fue incorporando en la vida económica, política y social del país. Se benefició de la promulgación de las leyes sociales para acceder a una legislación apropiada en el Código de Trabajo y luego alcanzó independencia con la Ley de Asociaciones Cooperativas. Esa normativa legal se ha enriquecido, hasta el presente, por las nuevas leyes que han fortalecido al cooperativismo, como por la suma de los criterios acertados de los tribunales de Justicia, la Procuraduría General de la República y la actividad del Instituto Nacional de Fomento Cooperativo, en cumplimiento de su función consultiva de la interpretación y aplicación de las normas de derecho cooperativo.

Derechos y deberes de las cooperativas, así como la búsqueda de mejores condiciones para ciertos grupos de las mismas, forman parte de la historia del Cooperativismo costarricense, y se presenta en este ensayo, con la conciencia de su brevedad, pero con la entrega de fuentes de científicas que permitirán al lector ampliar los conceptos que sean de su interés.

\section{Antecedentes legislativos siglos Xx y Xxı. Naturaleza jurídica de las cooperativas en Costa Rica.}

\section{Normativa actual cooperativa: la Ley de Asociaciones Cooperativas, normas conexas y afines}

Durante la primera mitad del siglo $\mathbf{x x}$, el cooperativismo costarricense vivió sus primeras experiencias y concretó diversos proyectos. Según la visión analítica de Aguilar y Fallas, el contexto de la sociedad costarricense se caracterizó por su dificultad económica y por esa razón "los proyectos cooperativos tenían el propósito de buscar solución a determinados problemas: la agricultura y comercialización del café, el ahorro, la carestía habitacional, etc." (1990, p.363).

Revisando la historia del cooperativismo en Costa Rica, Corella opina sobre la falta de un desarrollo sostenido, dado que "la realidad que ha tenido el cooperativismo costarricense, que no se ha comportado como una curva ascendente, sino, 
como una ola, con altos y bajos muy pronunciados." (2017, p. 18). El autor ubica el origen de las ideas cooperativistas como un fenómeno migratorio, justificado en la filiación europea, porque el cooperativismo "es hijo de las ideas socialistas que en su mayoría fueron importadas de Europa por costarricenses que estudiaban allá y leen documentos de los movimientos sociales que eran de moda en dicho continente". (Corella 2017, p.96).

Durante el periodo de 1907 a 1943 el cooperativismo costarricense no tuvo una legislación propia, sin embargo, su ausencia no obstaculizó el surgimiento de cooperativas, donde primaron aquellas dedicadas al consumo, de leche, de ahorro y de café. La evolución del cooperativismo, en ese período, fue la producción ideológica, muy rica, que ofreció sus bases dentro de la corriente social demócrata, de cuyo seno nació el partido político con más años de existencia en el país, denominado Liberación Nacional.

Previamente a la promulgación del Código de Trabajo en 1943, que incluyó el capítulo III, sobre las cooperativas, un grupo de jóvenes intelectuales, pensadores y académicos contribuyeron en forma constante en la elaboración de los fundamentos ideológicos del cooperativismo de la época. Ese grupo conformó el Centro de Estudios de los Problemas Nacionales, y de 1940 a 1943 sus miembros preocupados por las graves dificultades que afrontaba el país, provocadas en parte por la presencia y labor reivindicativa del Partido Comunista, según Chacón y Li (2015)ำ contribuyeron con la elaboración de un proyecto de cooperativas, dentro de una coyuntura política abierta a la legislación de tipo social. Esas bases ideológicas tenían un grupo meta determinado, según Núñez (citado por Vega, E. 2006, p. 23), quien en su artículo, publicado en el siglo XXX, analiza la labor de uno de sus miembros más activos del Centro, Rodrigo Facio, fundador del Partido Liberación Nacional, de corte socialdemócrata en sus primeros años de existencia. Según Núñez, tales bases ideológicas estaban dirigidas a un segmento muy definido de la población, en su artículo "Los planteamientos de Rodrigo Facio sobre el modelo cooperativo, y su coexistencia con el gran capital", publicado en la Revista Horizontes Cooperativos, 13, concluye:

1 En la conyuntura política de los años cuarenta, el Partido Comunista propugnaba por una propiedad social, según indican Castro y Li $(2015$, s.p. ) y el Cooperativismo era la forma organizativa más apropiada para oponerse a ese tipo de idea, proponiendo una propiedad colectiva de tipo privado. Y agregan que: Una de las formas de contrarrestar el apoyo popular que tenía el Partido Comunista, que ya contaba con sindicatos organizados de trabajadores, fue alentar o incentivar otro tipo de organización que defendiera la propiedad como una forma de organización social y que fuera una opción real para la convulsa Costa Rica de esos días, con la finalidad de que la sociedad en su conjunto rechazara las ideas socialistas. Esa opción fue el cooperativismo." 
El planteamiento de Facio, no solo en el campo cooperativo sino en general, representa prioritariamente las aspiraciones de los pequeños empresarios agrícolas e industriales,...pero por su misma naturaleza, han servido a desarrollar empresas en que los socios con mayores recursos hegemonizan y orientan la cooperativa en función de sus intereses. (citado por Vega, E. 2006, p. 23).

Dentro de las formas de integración cooperativa, el legislador de 1943 previó la existencia de uniones que podían nacer de "convenios circunstanciales" para el mejor cumplimiento y mayor efectividad de su acción. También se previó la existencia de federaciones como uniones permanentes para facilitar las operaciones de sus afiliadas y ampliar o realizar aún más eficazmente los fines sociales de la cooperación (artículo 360 C.T.).

De acuerdo con los autores mencionados (1990, p.469) hasta 1962 nacen y se desarrollan los organismos de segundo grado dentro del cooperativismo costarricense, año en que se fundó la Federación de Cooperativas de Caficultores R.L; y en 1963, nació la Cooperativa de Ahorro y Crédito y Servicios Múltiples de Costa Rica R.L., ambas actualmente extintas.

Los años sesenta y setenta del siglo xx fueron de gran crecimiento cooperativo. Con legislación adecuada y el apoyo del Estado, considera Corella, "el cooperativismo costarricense logra consolidarse y ser una alternativa de cambio social para la ciudadanía" (2017, p.96). Es a finales de la década de los años setenta, en 1968, cuando el legislador cambia de posición respecto de la naturaleza jurídica de las cooperativas, cuya base de creación había sido el esquema de las sociedades mercantiles, en especial las denominadas sociedades anónimas, según se puede deducir al revisar la sección de normas de integración legal, artículo 362 del Código de Trabajo, porque remite a ese tipo de sociedades para solucionar las lagunas existentes en el código.

Con el ascenso al Poder Ejecutivo de Luis Alberto Monge (1982-86), el cooperativismo recibió un abierto y decidido respaldo. En 1982 se promulgó el Reglamento de Cooperativas juveniles, a efecto de dar participación real a la juventud del país en el movimiento. Además, en 1983, se dieron más acciones de fortalecimiento del cooperativismo nacional, como indican los autores mencionados, dado que por la Ley 6839 de 1983 se otorgaron determinadas rentas al Centro de Estudios y Capacitación Cooperativa, nacido en el seno del Instituto Nacional de Fomento Cooperativo (INFOCOOP), se le traspasó la propiedad del Hotel del Sur, con el objetivo de dar un 
impulso vital y definitivo a la enseñanza del cooperativismo en Costa Rica. (Aguilar y Fallas, 1990, p.534)

Corella llama la atención respecto del cambio operado en el Estado, dado que "A finales de la década de los ochenta, surge la peor crisis del cooperativismo, el Estado se aleja del apoyo al modelo cooperativo, impulsado quizá por las ideas neoliberales que comenzaron a tomar fuerza en Costa Rica" (2017, p.96). Sin embargo, se debe tomar distancia de esa opinión, pues se mantiene el reconocimiento de la actividad no lucrativa de las cooperativas, que las mantiene exoneradas del pago del impuesto de renta hasta el presente (2018). También se mantiene la entrega de sumas millonarias de colones INFOCOOP por medio de transferencias y leyes que recaudan impuestos a favor del cooperativismo costarricense, dinero que se utiliza para darle capacitación y créditos blandos. Por ejemplo, el artículo 178 de la Ley de Asociaciones Cooperativas (LAC, 1968), en sus incisos c y d, establece un aporte anual equivalente al $10 \%$ de las utilidades que produzcan las instituciones del Estado que forman parte del Sistema Bancario Nacional, incluyendo al Banco Central de Costa Rica como organismo rector del sistema y, en el inciso d, un $40 \%$ de lo recaudado en la venta de refrescos gaseosos que determina la Ley 3021 del 21 de agosto de 1962.

Además, las políticas fiscales favorables a las cooperativas permiten que estas faciliten a sus asociados mejores servicios a precios razonables, que a la vez se traducen en beneficios sociales que permiten a las cooperativas realizar acciones de bien común que multiplican los impactos en los sectores donde operan las cooperativas (Corella, 2017, p.97).

De los datos frescos de la situación del cooperativismo costarricense, en un estudio de 2017, éste representaba el 40 \% de la Población Económicamente Activa y el 21 \% de la población nacional. A partir de esos datos, en la Dirección del Programa The Social Progress Imperative ${ }^{2}$, se realizó una investigación en doce cantones de 81 que tiene Costa Rica, con el fin de medir el impacto de las cooperativas en el progreso social de esos cantones y en opinión de Rodolfo Navas, Gerente de CENECOOP R.L, fue "la primera vez que se hace un ejercicio para medir el IPS en un modelo productivo como el cooperativismo" (CENECOOP R.L, 2017, p. 9)

2EI IPS es una iniciativa de la organización llamada Social Progress Imperative impulsada por investigadores de la Universidad de Harvard, Oxford y el Massachusetts Institute of Technology. Consiste en un proceso metodológico riguroso que mide el desempeño en tres dimensiones -necesidades básicas, fundamentos de bienestar y oportunidades-divididas en doce componentes o indicadores sociales y ambientales. Se refiere al lector interesado en ampliar más el conocimiento de esta herramienta de investigación, a la publicación citada: Centro de estudios cooperativos R.L. (CENECOoP R.L.) (2017) Estudio de los Indicadores de Progreso Social en zonas de incidencia del Cooperativismo en Costa Rica. Investigación de Índice de Progreso Social en comunidades cooperativas y no cooperativas. Revista Horizontes Cooperativos, 23. 
El final la investigación arrojó algunas tendencias que han sido divididas por el estudio en tres grupos de cantones, que parte de una conclusión general y dos conclusiones finales que se convierten en recomendaciones. La actualidad que mantiene esta investigación sobre las condiciones del cooperativismo costarricense, en los aspectos estudiados según los indicadores incluidos, hace manifiesta la posición del cooperativismo costarricense, dado que según el estudio mencionado existe una opinión indiscutible e inequívoca sobre su liderazgo social y como factor fundamental de desarrollo en los cantones donde han funcionado las cooperativas en las últimas décadas (CENECOOP R.L., 2017, p. 52)

La división de los cantones surge de los diferentes matices e intensidades en que se basa esa opinión, calificada en el estudio como convicción. Los tres tipos de cantones son:

1. Cantones en los cuales el cooperativismo ha sido fundamental para potenciar el desarrollo económico y, por tanto, social en conglomerados relativamente grandes. Según lo indicado en ese resultado de la investigación, tales cantones han sido típica e históricamente cooperativos desde su nacimiento y dedicados a ofrecer soluciones para la producción -café, caña de azúcar, leche, entre otros- (p. 52).

2. Cantones en que el cooperativismo surge como alternativa ante crisis y situaciones especiales. Corresponde al grupo de cooperativas que nacen por el abandono de las plantaciones por parte de las transnacionales dedicadas históricamente a la producción de banano y palma africana, dado que la mayoría de las principales actividades de la población-comercio, servicios de salud, actividades deportivas y recreativas- estaban en manos de la compañía (CENECOOP R.L., 2017, p.53). El resultado desde el punto de vista de la investigación es que al ser los miembros de esas cooperativas tanto trabajadores como propietarios "el espíritu cooperativo es más profundo y la relación con la cooperativa más intensa" (p. 53).

3. Cantones donde, de acuerdo con el tipo de cooperativas, el cooperativismo tiene un impacto menor sobre las familias, aunque contribuyen al desarrollo del cantón. 


\section{Normativa actual cooperativa: la Ley de Asociaciones Cooperativas, normas conexas y afines. Propuestas de reforma general a la LAC.}

En 1968 se dictó la primera ley que reguló, en forma autónoma y con un orden propio, la materia cooperativa, denominada Ley 4179 de Asociaciones Cooperativas y creación de INFOCOOP. En los años subsiguientes, ese cuerpo normativo se reformó, utilizando el camino de la promulgación de una nueva ley cada vez que se modificaba. Obviamente no era una reforma integral, pues se introdujeron reformas parciales sin variación de fondo. Salvo en 1982, cuando nacieron las cooperativas autogestionarias y cogestionarias, presentadas como un modelo nuevo de propiedad, fundamentalmente de la economía costarricense (Sánchez y Mayorga, 1988, p. 6).

Al presente han transcurrido cincuenta años desde la existencia de esa ley sobre asociaciones cooperativas, la cual cambió la naturaleza jurídica de las cooperativas porque dejaron de ser sociedades para convertirse en asociaciones cooperativas con su propia y autónoma regulación. Aparece un concepto mejor definido de la organización cooperativa, en el artículo dos y en el artículo tres, donde se introducen los principios cooperativos vigentes, que datan de 1966 (ver referencia ACI). Se establece una clara diferenciación entre las uniones y las federaciones cooperativas, se regulan sus requisitos de creación y funcionamiento (artículos 94 a 96).

Si se confronta la definición de cooperativa aprobada por la Alianza Cooperativa Internacional (ACI), en 1995, e incorporada en la Declaración de Identidad Cooperativa adoptada por la II Asamblea General, no se observa gran diferencia en cuanto a su contenido, $\mathrm{ACl}$ la define como una asociación autónoma de personas unidas voluntariamente para hacer frente a sus necesidades de tipo económico-social, y controlada democráticamente. (ACl, 2018), de tal modo que en relación con la definición existente en el Código de Trabajo promulgado en 1943, se puede observar un gran avance en cuanto a la precisión de la naturaleza jurídica de los fines de las cooperativas así como de la función social (artículo 2 de la LAC)

Costa Rica abandona el esquema mercantil para definir a la cooperativa, primero, como "asociación" y luego reconocer su integración con personas físicas, porque el artículo 2 indica que son "organizaciones de personas y no de capitales", con responsabilidad limitada,

Su objeto social es dotar a los asociados de trabajo, por ello el lucro no es el objetivo primordial de su creación y funcionamiento, sino la satisfacción de las 
necesidades de sus miembros y la promoción de su mejoramiento económico y social, como un medio de superar su condición humana y su formación individual, por medio del trabajo, la producción, la distribución y del consumo.

Existe el reconocimiento a las cooperativas, a los entes de integración y auxiliares su personalidad jurídica, caracterizadas por la autonomía frente al Estado y su organización democrática.

La LAC, promulgada en 1968, ha sido modificada en varias ocasiones, entre las reformas más importantes se puede contar la creación del INFOcooP y del Consejo Nacional de Cooperativas (CONACOOP) en 1973, la inclusión de dos nuevos modelos de cooperativas basados en la propiedad social: autogestión y cogestión, y la reforma al artículo 80 sobre la existencia del CENECOOP R.L. como organismo auxiliar cooperativo con derecho a los recursos provenientes de la contribución parafiscal de las cooperativas.

A partir de la declaración de identidad cooperativa de la Alianza Cooperativa Internacional en 1995 y la circulación del primer modelo de ley marco para las cooperativas de las Américas, formulado por la Organización de Cooperativas de América, se inició un trabajo importante dentro del cooperativismo nacional, en el nivel de cúpula del Consejo Nacional de Cooperativas. Trabajo dirigido a incorporar los nuevos contenidos de los valores y principios cooperativos, así como adecuar la legislación al modelo propuesto en la ley marco, con el fin de actualizar la ley y llenar algunas lagunas surgidas a causa de las novedades. Al comenzar el siglo XXI, se presentó como reforma integral a la LAC vigente, Ilamada Ley General de Cooperativas, bajo el expediente legislativo N. 14191, el cual no surtió frutos (Sánchez, 2009).

Aun cuando la legislación se mantiene sin cambios significativos en cuanto a la introducción de nuevos conceptos de la doctrina cooperativa basada en las decisiones asumidas por la ACI en Manchester, en 1985 y las sugerencias de la Ley Marco para las Cooperativas de América, como serían los nuevos principios cooperativos y el concepto de acto cooperativo, el cooperativismo costarricense no ha dejado de crecer y desarrollarse en forma sostenida y con buenos resultados. 


\section{La organización político-económica del cooperativismo costarricense:}

\section{Consejo Nacional de Cooperativas, cooperativas de base, federaciones, uniones, organismos auxiliares. Presión de los sectores de ahorro y crédito y las mujeres cooperativistas para una mejor integración política}

Una de las modificaciones más importantes para la organización política del cooperativismo costarricense fue la creación del CONACOOP como ente de representación y defensa de los intereses de sus miembros. Para comprender cuáles son esos miembros y en qué forma se han agrupado, es importante conocer la estructura organizativa del conjunto del sector cooperativista, establecida por la LAC, la cual se ha mantenido integrada por tres niveles:

1. Cooperativas de base que desarrollan todo tipo de actividad económica lícita.

2. Organismos de segundo grado, sean federaciones o uniones de cooperativas.

3. Confederaciones sectoriales que deberían estar formadas por las cooperativas de autogestión, por las cooperativas de cogestión y por las cooperativas denominadas las demás cooperativas y que se encuentran integradas en el Consejo Nacional de Cooperativas.

Las cooperativas de base están formadas por personas físicas, menores de dieciocho años, si son miembros de cooperativas escolares o juveniles. En las cuales el tipo de cooperativa tradicional requiere de veinte asociados como mínimo y las de autogestión de doce miembros como mínimo para su constitución y funcionamiento. Los organismos de segundo grado pueden ser federaciones o uniones. Las federaciones se constituyen por cooperativas del mismo sector económico y las uniones integran, en forma horizontal, cooperativas de diferentes sectores económicos. En opinión de Vega y Castro "además de las funciones de coordinación y prestación de servicios a sus afiliadas, los organismos de integración cumplen tareas de representación y defensa, que no solo realizan en el plano económico sino también en la esfera política" (1988, p.368).

Aparte de las federaciones y uniones, existen los organismos cooperativos auxiliares, o consorcios, en palabras de Vega y Castro su surgimiento "[...] obedece a un nuevo planteamiento cooperativista que le da un mayor énfasis a los aspectos 
económicos y empresariales, en contraposición a la concepción tradicional que priorizaba la dimensión social del cooperativismo" (1988, p.421). El organismo auxiliar que ha permanecido durante décadas, pues nació en 1982, ha sido el CENECOOP R.L., el cual se financia hasta con el $2.5 \%$ de los excedentes líquidos de las cooperativas. Su función es el desarrollo de la educación cooperativa en el país. Esa contribución en algún momento de la vida del CENECOOP R.L. fue considerada inconstitucional, dado que su destino es para sostener un ente privad. La pugna se dio en el seno del INFOCOOP, que se sostuvo que el CENECOOP sin las siglas de R.L, que indica su responsabilidad limitada, existía por ley dentro del mismo instituto, por lo tanto, los recursos debían ser entregados y controlados por esa institución pública. Sin embargo, la Sala Constitucional en su Voto 08587-2002 de 4 de setiembre de 2002, dejó clara la posición del Estado frente a la educación y capacitación cooperativa, así como la naturaleza de esa contribución, a la cual se le calificó de "parafiscal" por ser una verdadera contribución con claros fines económicos-sociales. Con ello se legitimó la existencia del CENECOOP R.L y la entrega de esas sumas para el cumplimiento de su objetivo.

La entrega de recursos provenientes de las cooperativas al CENECOOP R.L. continuó siendo cuestionada, y fue necesaria una reforma al artículo 80 de la LAC. Ley 8949 de 2011, mediante la cual la Asamblea Legislativa hizo una interpretación auténtica, estableciendo que sólo el organismo auxiliar de las cooperativas denominado CENECOOP R.L. es el beneficiario de los recursos otorgados por la $L A C$, dado que en el INFOCOOP funcionaba una oficina administrativa denominada CENECOOP sin las siglas R.L. El último intento para eliminar esos pagos y la transferencia del 1,5\% del presupuesto del instituto, se presentó en el expediente legislativo 20.217, lo cual al momento no ha prosperado.

\section{El Consejo Nacional de Cooperativas (CONACOOP) como organismo de representación nacional}

Como entidad deliberativa y representativa del cooperativismo nacional nació, en 1973, el CONACOOP como un organismo de delegados del sector cooperativo, con personería jurídica propia y carácter de ente público no estatal (artículo 136 de LAC). Además, se definió claramente su función en la elaboración de políticas y vigilante de la actuación del INFOCOOP, a través del nombramiento de cuatro representantes en su Junta Directiva. 
Para efectos de representación dentro de los órganos del CONACOOP, las cooperativas de primer y segundo grado fueron clasificadas en diferentes formas: grupo de las cooperativas agrícolas e industriales. Por modelo de propiedad social a las cooperativas autogestionarias y el denominado "demás cooperativas, que comprende todas las otras actividades económicas que realizan -incluidas las cooperativas de ahorro y crédito conocidas también como de intermediación financiera-. Cada sector tiene una asamblea independiente, con participación de todas las cooperativas y eligen diez representantes para formar parte del Plenario, cuyo número de miembros se amplía por la participación de organismos cooperativos sean federaciones o uniones en el nivel nacional, "designando cada una de ellas libremente un representante [...]" (Mayorga y Sánchez, p. 204). Del seno del Plenario se nombran los miembros del Directorio y representantes en diferentes instituciones autónomas del Estado. El Directorio es el órgano encargado de dirigir el cooperativismo cuando no está reunido el Plenario.

Al cooperativismo autogestionario se le concedieron mayores espacios políticos y económicos, si se compara con el resto de las cooperativas, el título II en la $L A C$ regula su relación con el CONACOOP, a través de la creación de un ente con bastante autonomía, denominado la Comisión Permanente de Cooperativas de Autogestión, se crea un fondo nacional de cooperativas de autogestión con recursos propios para el sector. La Comisión cumple, principalmente, la función de representación, coordinación y sirve de organismo representativo, coordinador y asesor de esas cooperativas y da la definición de las políticas de administración del Fondo (artículos 140-183 de LAC).

Cada año el CONACOOP debe realizar un congreso nacional cooperativo, con el fin de establecer las políticas del sector, en el cual participan todas las cooperativas y llevan definidas cuáles son sus prioridades de desarrollo económico y social (artículo 137 inciso e). En ese importante espacio de toma de decisiones, el V Congreso nacional de cooperativas de 1985, fueron creados los Consejos Regionales, como entes de defensa y representación regionales que deben impulsar cada una a través de la planificación y ejecución de las políticas asumidas por el conACOOP (Mayorga y Sánchez, p. 211)

El cooperativismo costarricense se ha ido posicionando en diferentes entes del Estado, por medio de los representantes elegidos por el CONACOOP, quienes con su voz y voto atraen recursos económicos y sociales según los sectores productivos de las cooperativas.

Realizan el nombramiento de un representante elegido por el CONACOOP en la Junta Directiva de la Caja Costarricense de Seguro Social, creada por Ley 17 de 1943 
institución encargada de la seguridad social del país y los recursos económicos para financiar vivienda.

Las cooperativas de pequeños agricultores cuentan con un representante en el Programa Integral de Mercadeo Agropecuario (PIMA) creado por la Ley Orgánica del Consejo Nacional de Producción N. 2035 de 1956. Ente representativo de diferentes sectores que integra los sectores: cooperativo, bancario, municipal, de agricultura, de comercio exterior, en beneficio de las PYMEs - pequeñas y medianas empresas- y organizaciones agrícolas.

El cooperativismo tiene una activa participación en otro ente público no estatal denominado Banco Popular y de Desarrollo Comunal, creado por Ley 4351 de 1969 y sus reformas. Es dirigido por una Junta Directiva nacional, una Asamblea de trabajadores y un Directorio. En la Asamblea el cooperativismo está representado por cooperativistas que contribuyan a formar el capital del banco y puede optar por tener miembros nombrados en las instancias político y económicas del Banco.

Con la creación del INFOCOOP el sector cooperativo obtuvo cuatro puestos de siete en su Junta Directiva, elegidos del seno del Plenario del conacoop, que representan a los sectores agrícola-industrial, autogestión y demás cooperativas; el cuarto es de nombramiento libre y sin sector definido. Esta participación tiene gran relevancia para el cooperativismo, en el tanto que pueden acceder a financiamiento en excelentes condiciones además de aprovechar el fomento y capacitación que ofrece el instituto.

En el campo de la formación y capacitación técnica, el cooperativismo también tiene acceso a los beneficios que ofrece al país por medio del Instituto Nacional de Aprendizaje, creado por Ley 6868 en 1983, encargado de promover y desarrollar la capacitación y formación profesional de los trabajadores, en todos los sectores de la economía, para impulsar el desarrollo económico y contribuir al mejoramiento de las condiciones de vida y de trabajo del pueblo costarricense. La participación en la Junta Directiva se logra por medio de la elección de un representante, escogido de la terna enviada por el CONACOOP al Poder Ejecutivo.

Para el sector agrícola-industrial es de gran importancia su representación en la Junta Directiva en el Servicio Nacional de Riego de Aguas y Avenamiento (SENARA), entre sus objetivos tiene procurar la creación de distritos de riego y avenamiento por Ley 6877 de 18 de julio de 1983.

Del recuento de representaciones del cooperativismo en las instituciones, programas y entidad financiera, se puede observar que ha ganado múltiples espacios de representación política que le permite acceder a recursos económicos con mayor facilidad que otros sectores productivos del país. Tal expansión en el ámbito 
nacional no se ha manifestado en igual forma al interno de las representaciones de sectores del cooperativismo que han crecido notablemente, ya sea por el tipo de actividad económico social que realizan, como son las cooperativas de ahorro y crédito; o por razones de real participación de las mujeres, tal y como se podrá conocer en el siguiente aparte.

\title{
Presiones para ampliar los sectores con representación política dentro del CONACOOP.
}

\author{
Propuesta de una asamblea de cooperativas de ahorro y crédito \\ y creación del Comité Nacional de las Mujeres Cooperativistas \\ para asegurar la equidad e igualdad de género. atisbos en el \\ sector de economía social
}

En este siglo XXI, dos grupos de cooperativas han impulsado proyectos de ley para modificar la integración del CONACOOP, de acuerdo con lo establecido en la LAC, para obtener una participación más directa en el Plenario y, de ser posible, en la Junta Directiva del INFOCOOP, en forma directa y sin competencia con los otros sectores. El primer grupo lo forman las cooperativas de ahorro y crédito. El otro grupo, independientemente de la calificación de las cooperativas en relación con los sectores productivos, algunas las mujeres cooperativistas dan la lucha por obtener escaños políticos que les den estabilidad, seguridad y acceso a los recursos económicos asignados al CONACOOP, por medio de la creación de un órgano especializado en temas de mujer cooperativista.

En relación con el sector de cooperativas de ahorro y crédito, se dieron dos intentos de reforma parcial a la LAC, con el objetivo de introducir un nuevo sector, con su propia asamblea dentro de la organización del CONACOOP. El primer proyecto fue presentado en el 2008 bajo el Expediente Legislativo N. 17187 y se le denominó "Fortalecimiento del sector de ahorro y crédito", el cual no tuvo éxito. En una segunda ocasión se presentó el proyecto N. 18479 de 2013, con la fortaleza de haber obtenido un dictamen de mayoría en la Asamblea Legislativa y al interno del CONACOOP, y el reconocimiento en el XII Congreso Cooperativo Nacional de la necesidad de crear ese cuarto sector cooperativo e incluir un representante propio ante la Junta Directiva del INFOCOOP. 
La propuesta de las reformas se basó en el Censo Cooperativo de 2008 que mostró algunos datos y, en opinión de los proponentes, permitían deducir el peso específico de ese sector dentro del cooperativismo: por número de cooperativas, de asociados, además del volumen de operaciones financieras. Así, en ese momento, en cuanto al número, las cooperativas tradicionales -léase "demás cooperativas" - eran 257 , de las cuales el $48 \%$ de la totalidad eran cooperativas de ahorro y crédito y por lo tanto representaban más de una tercera parte. En cuanto al número de asociados, ese sector tenía un total de 554.865 asociados que representaba el $73 \%$ de la totalidad de asociados del cooperativismo. En cuanto al aspecto económico, el censo cooperativo reflejó que el sector financiero cooperativo constituía el de mayor tasa de crecimiento y frente al sector financiero nacional, en ese momento, esa tasa representaba un crecimiento del $48 \%$.

Por parte de las mujeres cooperativistas la batalla por obtener representación directa y permanente en el CONACOOP está unida en el nivel nacional, junto con la búsqueda de llevar a la realidad las múltiples leyes para la protección jurídica y económica de las mujeres. Por ejemplo, la Convección para la Eliminación de toda Forma de Discriminación contra las Mujeres (CEDAW, 1984), fue incorporada como ley del país, y pese a una extensa doctrina y jurisprudencia de la Sala Constitucional, las mujeres cooperativistas siguen luchando por obtener un trato más equitativo en cuanto a la distribución de puestos y beneficios dentro de cooperativismo. Más allá del cooperativismo, el entorno legislativo del país ha sido favorable al reconocimiento de los derechos políticos y económicos de la mujer y se han dado las siguientes leyes: Ley 8322 de 2002, reformó la Ley del Banco Popular y Desarrollo Comunal (BPDC) otorgando la paridad en todas las estructuras de decisión; Ley 8765 de 2009 Código Electoral, que obliga a cumplir con la paridad, en todas las estructuras de decisión de los partidos políticos y en todas las nóminas de elección popular; Ley 8901 de 2010 que introdujo la paridad en las Juntas Directivas de diferentes sectores sociales -asociaciones civiles, asociaciones solidaristas, asociaciones comunales y sindicatos-.

El último intento de mejorar las condiciones antes expresadas fue la presentación a la corriente legislativa del proyecto de ley denominado "Democratización de las diferentes instancias de decisión del movimiento cooperativo y creación del Comité nacional de las mujeres cooperativistas (CONAMUJER)" expediente legislativo No. 18.199 de 2011, modificado su nombre por un nuevo proyecto denominado "Reforma de la LAC y creación del INFOCOOP, No. 4179, del 22/8/1968" y adición de un nuevo título IV para creación de un Comité nacional para la equidad e igualdad de género y los Derechos Humanos de las mujeres del Movimiento Cooperativo presentado en el 2013. Ambos proyectos pretenden reformar la actual LAC, con la incorporación de las mujeres en 
diferentes instancias del cooperativismo y lograr el cumplimiento de los compromisos contraídos por el máximo ente decisorio del cooperativismo costarricense, el Congreso Nacional Cooperativo, asimilándolo al logro en el BPDC, Ley 8322 de 2002, antes mencionada (Sánchez, 2005)

De la lucha de los sectores mencionados se puede notar la falta de voluntad legislativa para aprobarlos, así como un real interés del resto de sectores del cooperativismo nacional, indudablemente, ambos proyectos representan una amenaza para la posición en que se encuentran las cooperativas agrícola-industrial y autogestionarias, y sus puestos en la Junta Directiva del INFOcOOP. Por parte del grupo de mujeres cooperativistas, la amenaza es para todo el cooperativismo de género masculino, en el tanto que se le reconocería derechos de participación política y económica por razón de su género femenino. Así los mandatos de los congresos cooperativos tienen rango de ley según el artículo 137 (inciso e), donde LAC responden en forma fiel a las órdenes dadas por la Asamblea de delegados cooperativistas, a través de los congresos, por lo cual los diputados están legitimados dentro del bloque de legalidad cooperativa, a dictar la normativa legal necesaria para su cumplimiento.

\section{Proyecto de ley para la creación de un sector de economía solidaria}

El concepto más reciente sobre economía social nace en Francia, en los años setenta, caracterizado por elementos que han sido plasmados, por ejemplo, en políticas comunitarias europeas y han servido de guía a los países que integran la Unión Europea y como base doctrinaria a muchos de los interesados en impulsar la creación de un sector de economía social, en su país. Como es el caso costarricense, donde si bien han existido iniciativas para apoyar empresarialmente a los trabajadores de relación laboral subordinada, solo hasta la propuesta del proyecto de Ley marco de economía solidaria presentado en el 2016, es cuando se ha perfilado mejor el concepto de economía social más aceptado y difundido. Así Llamosas (2018, p.34) parte de la identificación de la economía social según el concepto nacido en el seno del Comité National de Liaison des Activités Cooperatives, Mutuelles et Associatives, de los años setenta en el siglo XX, que fue básico para llegar a la Carta de los Principios de Economía Social del 2002, redactada por la Conferencia Europea permanente de las cooperativas, mutuas, asociaciones y fundaciones, a saber:

1. La primacía de la persona y de los fines sociales sobre el capital.

2. La adhesión y la participación libre y voluntaria. 
3. El control democrático por parte de los socios.

4. La conciliación de los intereses del socio con los intereses generales.

5. El respeto a los principios de responsabilidad y solidaridad.

6. La gestión autónoma e independiente respecto a las autoridades de carácter público.

7. La destinación de los beneficios al desarrollo y consecución de los fines.

En Costa Rica la conformación de un sector de economía social encuentra sus antecedentes en 1950 cuando Alberto Martén propuso crear un sector de economía laboral que se nutriría de los recursos provenientes de la cesantía. Era un derecho de los trabajadores en la relación laboral subordinada, al pago de una suma determinada, que conservaban los empleadores durante todos los años de existencia de la relación laboral y entregaban únicamente en caso de despedido injustificado. La idea de Martén era pasar de tener trabajadores subordinados a empresarios, por medio del desarrollo de empresas de trabajadores, su lema era "más propietarios y menos proletarios" (Sánchez, 1986).

Pese a las múltiples discusiones de los sectores empresariales en el ámbito nacional, en contra, y algunos sectores laborales a favor, no se hizo ninguna modificación en la normativa laboral. Al presente, el único espacio donde confluyen y se integran varios sectores gremiales y productivos de la clase trabajadora: cooperativistas, sindicalistas, líderes de desarrollo comunal y artesanos, profesionales y sindicalistas es la Asamblea de trabajadores y trabajadoras del BPDC, en cuyo seno se decide sobre el destino de los recursos del Banco. Hasta el momento no se ha logrado conformar un sector de economía social, pues por parte del Estado no se ha impulsado una política pública que desarrolle y conserve tal sector y los mencionados grupos de trabajadores tampoco se han unido para impulsar la existencia del mismo.

En 2016, un grupo de diputados de extracción social demócrata presentaron el proyecto de ley marco de la economía solidaria (expediente No. 19.654), con una exposición de motivos que buscó sustentar el "asociativismo no lucrativo", con orígenes en la segunda mitad del siglo XIX y con gran similitud al modelo español de economía social. Ahí se ofrecen diversos ejemplos de normas atinentes a medianas y pequeñas empresas, sin posibilidad de integración en un solo sector de economía social. Se propone la creación de un Consejo Nacional de la Economía Social Solidaria (CONAESS), adscrito al Ministerio de Trabajo, para atender la formulación de políticas y estrategias para el fomento de organizaciones de economía social solidaria, como cooperativas, sindicatos, grupos solidaristas y asociaciones de productores. El proyecto pasó a estudio e informe de la Comisión Especial Dictaminadora el 27 de 
julio de 2016, con el objetivo de investigar, estudiar, analizar y dictaminar la legislación adecuada para el fortalecimiento del sector de la economía social solidaria, sin embargo, no se avanzó más. Existen férreas oposiciones en el conAcoop, que considera que su contenido ya está regulado por otras normas, y el Departamento de Servicios Técnicos de la Asamblea Legislativa, apuntó las duplicidades encontradas en el proyecto (El País, 2015). La Procuraduría General de la República, reforzó la tesis de la duplicidad de órganos, en especial los dedicados al registro de diferentes tipos de organizaciones sociales (Diario Ticodigital, 2016) y también se ha cuestionado a uno de los promotores del proyecto, diputado Morales Zapata, por su relación con un caso judicial de mucha envergadura para el país, que se desató en 2017 (Semanario Universidad, 2018).

\section{Límites impuestos a la actividad cooperativa.}

\section{Normativa del gobierno corporativo: seguridad, participación, información y formación de los miembros de una cooperativa y la responsabilidad de sus administradores. Aspectos contables y de la competencia que sujetan las cooperativas en Costa Rica}

Hasta este punto de la exposición sobre aspectos legales y políticos del cooperativismo costarricense, se puede concluir que ha sido un desarrollo económico y social, con grandes beneficios para sus miembros. Pero, Costa Rica no es una isla en el mercado mundial. Las experiencias de otros cooperativistas en el mundo, así como la revisión del comportamiento del crédito y el ahorro cooperativo abrieron espacios en el país para la promulgación de leyes y normas regulatorias para ese sector, que trajeron la exigencia de una mayor responsabilidad para los integrantes de los órganos sociales de las cooperativas mencionadas. Tampoco escapan las cooperativas en general, de la aplicación de las normas internacionales de contabilidad, pues son organizaciones económico-sociales, aunque hasta el momento no se les puede aplicar el principio de libre competencia por su definición de organización sin fines de lucro.

En 1994 se dictó la Ley 7391 de Regulación de Intermediación Financiera de Organizaciones Cooperativas, que reformó el artículo 21 de la LAC, con el fin de asegurar que las cooperativas de ese sector cumplieran con sus objetivos económicos y sociales y garantizaran a los asociados la más eficiente y segura administración de sus recursos. En el marco de acción de estas cooperativas quedó clara la definición de 
la actividad de intermediación financiera cooperativa, entendida como la realización de cualquier acto de captación de dinero de sus propios asociados, con el propósito de destinar esos recursos al otorgamiento de crédito o de inversión en el mercado financiero, cualquiera que sea el documento en que se formalice la operación, todo de conformidad con la definición de intermediación financiera establecida por el Banco Central de Costa Rica (artículo 3). Así otros artículos de la LAC fueron derogados, al establecerse el principio de especialidad en cuanto a la intermediación financiera, reservada únicamente a las cooperativas de ahorro y crédito, de tal modo que cooperativas de otros giros económicos que también realizaban esa función se vieron obligadas a cerrar sus secciones de ahorro y crédito.

Con esa ley, las cooperativas de ahorro y crédito comenzaron a ser supervisadas por la entidad gubernamental conocida actualmente como Superintendencia de Entidades Financieras (SUGEF), artículo 7 de la ley indicada, la cual pertenece al Consejo nacional de supervisión financiera y, en acatamiento a sus mandatos, promulgó el reglamento sobre gobierno corporativo, el 7 de diciembre de 2016. El punto de partida para modificar la normativa fue la crisis financiera de 2008, que puso en tela de juicio el desempeño de las empresas en términos de su gobernanza y del impacto que tiene sobre el desarrollo de los mercados de capitales en el mundo. De tal modo que, considerando las diferencias de las entidades supervisadas, se emitió tal reglamento que dejó atrás las formas prescriptivas y se basa en principios. La naturaleza y características del mercado financiero, en ese momento, y el necesario reconocimiento de las diferencias de las entidades que lo integraban, fueron parte de las consideraciones apuntadas por la SUGEF (2016, p.4). Como resultado del reglamento mencionado, cada cooperativa perteneciente a ese sector ha promulgado sus propias normas de gobierno corporativo. Tales regulaciones comprenden por ejemplo en COOPEAMISTAD R.L., un código de gobierno corporativo, un manual de políticas de gobierno corporativo y un código de ética, (2017). La obligación de informar supone que la cooperativa preserve la confidencialidad de la misma, así ésta sea momentánea. La cooperativa, en el ejercicio de su actividad, se compromete a aplicar el principio de transparencia en contratos, en promoción y en la publicidad, a la vez que se responsabiliza de instaurar y mantener un flujo informativo continuo, oportuno y puntual de información al mercado (COOPEAMISTAD R.L. Código de Gobierno Corporativo, 2017, pp.33-35).

En relación con la información contable y financiera que deben ofrecer las cooperativas, por la Ley 1038 de 1947, compete al Colegio de Contadores Públicos de Costa Rica establecer la forma y procedimiento de exposición y presentación de los estados financieros. Es así que desde el 2001, Costa Rica adoptó en forma total las Normas 
Internacionales de Información Financiera (NIIF), con el propósito de fomentar la calidad, comparabilidad, claridad y la transparencia en la preparación de los estados financieros de las empresas. Por parte del Colegio de Contadores Públicos, se considera que las NIIF no están diseñadas para ser aplicadas a las entidades sin ánimo de lucro. Sin embargo, en Costa Rica, el marco de referencia para las empresas en general son esas normas, por lo que de acuerdo con los lineamientos del colegio mencionado y de la Administración Tributaria, las cooperativas están obligadas a llevar sus registros contables con base en las NIIF. Aunque se permite a las cooperativas acogerse a la normativa que cubre las NIIF PYMES, para lo cual deben cumplir con los requisitos de inscripción tal y como lo establece el Ministerio de Economía, Industria y Comercio (MEIC) (INFOCOOP, 2016). La LAC recalca de forma clara e indiscutible la naturaleza y la finalidad los entes cooperativos, que consiste en brindar un servicio a sus asociados como propietarios de la cooperativa y no la generación de lucro (artículos 2 y 78 de LAC).

Por medio de la Resolución No. 52-01 de la Dirección General de Tributación Directa del Ministerio de Hacienda, en acatamiento de las directrices del Colegio mencionado, los Estados Financieros de las cooperativas deben preparase de "conformidad con las Normas Internacionales de Contabilidad aprobadas y adoptadas por el Colegio de Contadores Públicos de Costa Rica". Sin posibilidad de elección para esas organizaciones, de elegir otra base contable más ventajosa, porque las NIIF fueron definidas de acatamiento obligatorio y su falta de cumplimiento debe ser revelado en un párrafo en la opinión del auditor que haya sido contratado por el ente cooperativo correspondiente.

Refieren Li y Ureña (s.a. p.7) que el colegio resolvió adoptar de pleno y parcialmente las NIIF. Entre el grupo de normas adoptadas de pleno se encuentra la NIC 32 "Instrumentos Financieros: Presentación e Información a revelar. A partir de la vigencia de la NIIF 7, en enero del 2007, se denominarás Instrumentos Financieros: Presentación". Esa decisión generó un temor entre las organizaciones cooperativas, entre otras, porque la NIC 32, de alguna forma, califica los aportes de los asociados a las cooperativas de ahorro y crédito como pasivo financiero y no como patrimonio, como siempre se ha considerado. Siguen explicando los autores, que en el caso de las cooperativas de ahorro y crédito abiertas, que se encuentran supervisadas por la Superintendencia de Entidades Financieras, la situación era más crítica, ya que de reclasificar los aportes patrimoniales como pasivos financieros, inmediatamente entraban en problemas de suficiencia patrimonial $-8 \%$ de los activos ponderados por riesgo, según la normativa vigente en ese momento-, lo que implicaba su intervención casi inmediata por parte del ente supervisor, y su quiebra inminente, por la estampida que se produciría entre sus socios ahorradores, por el temor de perder sus aportaciones. 
De tal modo que el sector cooperativo de ahorro y crédito pidió a ese colegio emitir un pronunciamiento para definir la obligatoriedad o no, de seguir las normas establecidas en la NIC 32. Así, por acuerdo No. 283-2007, el colegio estableció que tales organizaciones de acuerdo con su ley de creación, pueden exponer y presentar sus estados financieros incluyendo aportaciones sociales como capital social, dentro de su estructura patrimonial y deberán revelar como notas a los estados financieros la política contable aplicable a las aportaciones sociales, a así como el detalle de la conformación del patrimonio (Li y Ureña, s.a., pp.11-12).

La posición de las cooperativas ante las normas de la competencia del resto del mercado costarricense fue dilucidado por la Sala Constitucional en Voto 11640-2003, ante una acción de inconstitucionalidad. Ese tribunal considero que las cooperativas de ahorro y crédito, a diferencia de las sociedades anónimas que se dedican a la actividad financiera, no tienen fines de lucro, en virtud de lo dispuesto en los artículos 1, 2 y 21 de la Ley de Asociaciones Cooperativas, y pese a ser entes de carácter privado son de conveniencia, utilidad pública e interés social. El motivo del trabajo, la producción, la distribución y el consumo es el servicio y no la ganancia. Por esa razón, el principio de libre competencia no rige en las asociaciones cooperativas pues sus fines no se orientan a lo económico, sino a la satisfacción de las necesidades del ser humano, integralmente considerado. Por lo tanto, no existe violación del principio alegado, por cuanto las cooperativas no se encuentran en la misma situación de hecho que los demás entes de intermediación financiera.

\section{Conclusiones}

Como se apuntó, el cooperativismo costarricense no ha tenido un ascenso sostenido. Altos y bajos lo han caracterizado. En algunos casos, el vínculo directo de algún presidente del país, lo ha beneficiado con donaciones de inmuebles y estímulos económicos. En otros momentos, la influencia de las tendencias político-económicas ha disminuido el cooperativismo en el número de organizaciones sociales, que es una línea de investigación abierta para futuras contribuciones.

Los proyectos de adecuación de la ley a las normas de la ACI no han progresado. Hay pocas modificaciones legislativas, aunque las existentes son relevantes por el nacimiento del INFOCOOP y el CONACOOP, así como inserción de las cooperativas de ahorro y crédito dentro del sector de intermediación financiera, como un mecanismo de protección a sus miembros. Si bien, el cooperativismo costarricense ha sido prolífero en la búsqueda de oportunidades de negocios, por medio del nombramiento de representantes en instituciones estatales y el BPDC, que ha permitido una expansión 
y presencia al externo del mismo. Sin embargo, la búsqueda de mayor participación democrática del sector de ahorro y crédito y el grupo de mujeres cooperativistas no ha encontrado eco, pues los proyectos de ley no han sido apoyados realmente, aunque cuenten con acuerdos de los congresos nacionales cooperativos. El proyecto de creación de un sector de ahorro y crédito no se convirtió en ley y el de creación de CONAMUJER, ha pasado por varios gobiernos, sin obtener su la promulgación de la ley correspondiente.

Las investigaciones futuras deberán centrarse en las causas de la ausencia de la fuerza política dentro del cooperativismo para lograr el éxito de tales propuestas y dejar, obvio si fuere posible, que la conducta de algunos líderes no afecta la base cooperativa, que mantiene su posición en el mercado y la sociedad costarricense.

La creación de un sector de economía solidaria no es una prioridad para ninguno de los sectores que podría integrar, ni por parte del Estado, en realidad porque no ha existido una verdadera discusión y un verdadero análisis por parte de las organizaciones sociales que podrían formar ese sector, sobre los objetivos y beneficios que puede traer su creación legal.

Finalmente, cabe apuntar que las cooperativas de ahorro y crédito, tipificadas más de intermediación financiera, no pueden escapar a las directrices internacionales para este tipo de actividad económica, que desde el nivel interno han sido establecidas por la SUGEF. Es importante reiterar que la calificación de las cooperativas como entidades sin lucro, según criterio de la Sala Constitucional, que las deja fuera de las obligaciones establecidas en las NIIF, especialmente la norma NIC 32 no mercantil que tienen las sociedades comerciales en cuanto al respeto de la libre competencia.

\section{Siglas}

AMUCODE $\quad$ Asociación de Mujeres en Cooperación para el Desarrollo

BPDC

Ley del Banco Popular y Desarrollo Comunal

CEnecoop R.L. Centro de Estudios Cooperativos R.L

CNC Consejo Nacional de Concesiones

CONAMUJER Comité Nacional de las Mujeres Cooperativas 
CONACOOP Consejo Nacional de Cooperativas

INFOCOOP Instituto Nacional de Fomento Cooperativo

LAC Ley de Asociaciones Cooperativas

MEIC Ministerio de Economía, Industria y Comercio

PIMA Programa Integral de Mercadeo Agropecuario

PYMES Pequeñas y Medianas Empresas

SENARA Servicio Nacional de Aguas de Riego

SUGEF Superintendencia de Entidades Financieras

\section{Referencias}

Aguilar, O. y Fallas, C. (1990). El movimiento cooperativo en Costa Rica. Sus antecedentes en la historia universal. Costa Rica: Ed. Imprenta Nacional.

Alianza Cooperativa Internacional. (1985). Principios y valores cooperativos. Cooperativas de las Américas. Región de la ACl. Recuperado de: https://www.aciamericas.coop/ Principios-y-Valores-Cooperativos-4456

Asamblea Legislativa. (1984). Convección para la Eliminación de toda Forma de Discriminación contra las Mujeres (CEDAW). Costa Rica.

Asamblea Legislativa. (2002). Ley 8322. Ley de Democratización de las Instancias del Decisión del Banco Popular y de Desarrollo Comunal (Reforma a la Ley Orgánica del Banco Popular, N4351). Recuperado de:2018. http://www.pgrweb.go.cr/scij/Busqueda/Normativa/Normas/ nrm_texto_completo.aspx?param1=NRTC\&nValor1=1\&nValor2=49559\&nValor3=53016\& strTipM=TC

Asamblea Legislativa. (2008). Proyecto deleyn. 17187 del09/10/2008. Reforma parcial de la Ley de asociaciones cooperativas y creación del Instituto nacional de fomento cooperativo, n. ${ }^{\circ} 4179$, y sus reformas, cooperativo de ahorro y crédito. La Gaceta, 218. Recuperado de: https://cgrfiles.cgr. go.cr/publico/jaguar/USI/.../PROYECTO.../PROYECTO-17187.doc 
Asamblea Legislativa. (2009). Ley 8765. Código Electoral. Recuperado de: http://www.tse.go.cr/pdf/ normativa/codigoelectoral.pdf

Asamblea Legislativa. (2010). Ley 8901. Porcentaje mínimo de mujeres que deben integrar las Directivas de Asociaciones, Sindicatos y Asociaciones Solidaristas. Recuperado de: 2018. http://www.pgrweb.go.cr/scij/Busqueda/Normativa/Normas/nrm_norma.aspx?param1= NRM\&nValor1=1\&nValor2=69350\&nValor3=83258\&strTipM=FN

Asamblea Legislativa. (2011). Reforma al artículo 80 de la LAC. Ley 8949 de 2011. La Gaceta, 86 (5 de mayo).

Asamblea Legislativa. (2011). Democratización de las diferentes instancias de decisión del movimiento cooperativo y creación del Comité nacional de las mujeres cooperativistas. (CONAMUJER). Expediente No. 18.199. Biblioteca Asamblea Legislativa. Costa Rica.

Asamblea Legislativa. (2012). Reforma a la Ley de asociaciones cooperativas, Ley 4179, para fortalecer la participación del sector ahorro y crédito en los órganos de planificación y dirección del movimiento cooperativo costarricense. La Gaceta, 193. Recuperado de: http://www.asamblea.go.cr/glcp/Ordenes_dia/2013-2014-GOBIERNO\%20Y\%20 ADMINISTRACI\%C3\%93N-SESI\%C3\%93N-36.pdf

Asamblea Legislativa. (2013). Reforma parcial de la LAC para el fortalecimiento del Sector de ahorro y crédito expediente N. 17.187. Costa Rica: Biblioteca de la Asamblea Legislativa.

Asamblea Legislativa. (2016). Proyecto de Ley marco de la Economía Social Solidaria. Expediente N. ${ }^{\circ}$ 19.654. La Gaceta, 93. Recuperado de: http://proyectos.conare.ac.cr/asamblea/19654.pdf

Asamblea Legislativa. (2016). Proyecto Ley para eliminar el pago de 2,5\% de los excedentes de las cooperativas a CENECOOP R.L. y para eliminar la transferencia del 1,5\% del presupuesto de INFOCOOP paraCENECOOPR.L. Expediente legislativo No. 20.217. La Gaceta, 113. Recuperado de: https://www.imprentanacional.go.cr/pub/2017/06/15/ALCA142_15_06_2017.pdf

Centro de Estudios Cooperativos R.L. (Cenecoop R.L.). (2017). Estudio de los Indicadores de Progreso Social en zonas de incidencia del Cooperativismo en Costa Rica. Investigación de Índice de Progreso Social en comunidades cooperativas y no cooperativas. Revista Horizontes Cooperativos, 23. Costa Rica.

Coopeamistad, R.L. (2017). Gobierno corporativo. Recuperado de: http://www.coopeamistadrl. com/informes/gobierno-corporativo.html 
Corella, L. (2017). Apuntes para una economía cooperativa. Costa Rica: Ed. Atabal.

Diario Ticodigital. (2016). Polémico proyecto de Ley de Economía Social Solidaria avanza en la Asamblea. A criterio de cooperativas y Procuraduría, la iniciativa genera duplicidad de funciones con otras instituciones. Recuperado de: http://informa-tico.com/27-04-2016/ busca-ley-marco-economia-social-solidaria.

ElPaís.cr.(2015).CONACOOPrechazacreacióndeentequeveleporactividadesproductivas. Recuperado de: 2018. https://www.nacion.com/el-pais/politica/cooperativas-ven- innecesaria-unaley-de-economia-social/PQWH7K26FJDIBIQG7F5TBVQAAI/story/

El País.cr. (2018). Informe señala que en 10 años INFOCOOP manejó irregularmente 45 mil millones de colones. Recuperado de: https://www.elpais.cr/2018/04/09/informe-senala-queen-10-anos-infocoop-manejo-irregularmente-45-mil-millones-de-colones/

Fonseca, R. (2001). Manual de Derecho Cooperativo costarricense. Costa Rica: Ed. Guayacán.

Hernández, G y Li F. (2015). Antecedentes ideológicos del movimiento cooperativo en Costa Rica. Revista Idelcoop, 215. Recuperado de: https://elespiritudel48.org/antecedentesideologicos-del-movimiento-cooperativo-en-costa-rica/

Instituto Nacional de Fomento Cooperativo. (1993). Criterio emitido por el Departamento Legal del Instituto oficio AL- 676-93 de 29 de setiembre de 1993. Recuperado de: http://www.infocoop. go.cr/nuestros_servicios/supervision.html

Instituto Nacional de Fomento Cooperativo. (2012). Ley N. 4179 de Asociaciones Cooperativas y creación del INFOCOOP y otras normas conexas. Costa Rica: Ed. INFOCOOP.

Instituto Nacional de Fomento Cooperativo. (2016). Respuesta de Colegio de contadores públicos. 22 de febrero del 2016. SC-0203-746-2015. Recuperado de: http://www.infocoop.go.cr/nuestros_servicios/supervision.html

Llamosas, A. (2018). La Economía Social, una vía para la creación de un empleo estable y de calidad. Deusto Estudios Cooperativos, 10, 31-46.

Li,F.yUreñaM.(s.a.) Eltratodela NormaInternacionaldeContabilidad32enlascooperativasyasociacionessolidaristas en Costa Rica. Universidad Estatala Distancia. CostaRica. Recuperado de: http:// www.academia.edu/10341392/El_trato_de_la_Norma_Internacional_de_Contabilidad_ 32_en_las_cooperativas_y_asociaciones_solidaristas_en_Costa_Rica 
Mayorga, L. Y Sánchez, R. (1988). Cooperativismo costarricense. Panorama del desarrollo Cooperativismo en Costa Rica. Costa Rica: Ed. Universidad estatal a distancia.

Sánchez, R. (1986). El Proyecto de Creación del Sector de Economía Laboral. Intereses en Pugna y papel del Estado. Tesis. Costa Rica.

Sánchez, R. y Mayorga, L. (1988). Cooperativismo costarricense. Colección de leyes y Decretos y jurisprudencia administrativa sobre cooperativismo en Costa Rica. Costa Rica: Ed. Universidad estatal a distancia..

Sánchez, L.R. (2005). ¿Cómo se forjó la primera ley de Costa Rica donde se establece la paridad en las instancias políticas del Banco Popular y de Desarrollo Comunal? Recuperado de: neticoop.org.uy

Sánchez, R. (2009). Antecedentes de la legislación cooperativa costarricense. Boletín de la Asociación Internacional de Derecho Cooperativo, 43, 73-91.

Semanario Universidad. (2018). Con resistencia oficialista, diputados aprueban informe del 'Cementazo'. Recuperado de: https://semanariouniversidad.com/ultima-hora/resistenciaoficialista-diputados-aprueban-informe-del-cementazo/

Vega, E. (2005). Rodrigo Facio ¿Quién fue y que hizo? Costa Rica: Ed. Universidad estatal a distancia.

Vega, M. y Castro, C. (1988). La organización formal del cooperativismo e información básica sobre los organismos de segundo grado y auxiliares en Cooperativismo costarricense. Costa Rica: Ed. Universidad estatal a distancia.

\section{Legislación}

Asamblea Legislativa. (1888). Código Civil. Costa Rica: Ed. Imprenta Nacional.

Asamblea Legislativa. (1943). Código de Trabajo. Costa Rica: Ed. Imprenta Nacional.

Asamblea Legislativa. (1943). Ley constitutiva de la Caja costarricense de seguro social. N. 17. Recuperado de: http://www.pgrweb.go.cr/scij/Busqueda/Normativa/Normas/nrm_texto_ completo.aspx?param2=NRTC\&nValor $1=1 \& n$ Valor $2=2340 \&$ param $2=29 \&$ strTi pM=TC\&lResultado=287\&strSim=simp 
Asamblea Legislativa. (1969). Ley de creación del Banco popular y de desarrollo comunal. Ley No. 4351. Recuperado de: http://www.secmca.org/LEGISLACION/CR/LOBPDCostaRica.pdf

Asamblea Legislativa. 1983). Ley de Creación del Servicio Nacional de Aguas Subterráneas, Riego y Avenamiento (SENARA) No. 6877. (Recuperado de: http://www.senara.or.cr/acerca_del_senara/marco_legal/leyes_senara/6877\%20Ley\%20de\%20creacion\%20del\%20SENARA.pdf

Asamblea Legislativa. (1983). Ley orgánica del Instituto nacional de aprendizaje. N. 6868. Recuperado de: http://www.pgrweb.go.cr/scij/Busqueda/Normativa/Normas/nrm_texto_ completo.aspx?param1=NRTC\&nValor1=1\&nValor2=36651\&nValor3=38641\&strTipM=TC

Asamblea Legislativa. (1988). Código Tributario. Ley 7092. Recuperado de: http:// www.pgrweb.go.cr/scij/Busqueda/Normativa/Normas/nrm_texto_completo. aspx?param1=NRTC\&nValor1=1\&nValor2=10969\&nValor3=105707\&strTipM=TC

Asamblea Legislativa. (1994). Ley de Regulación de Intermediación Financiera de Organizaciones Cooperativas No. 7391. Costa Rica: Imprenta Nacional.

Asamblea Legislativa. (2000)Ley de Protección al trabajador.. Ley N. 7980-2000. Recuperado de: http://www.pgrweb.go.cr/scij/Busqueda/Normativa/Normas/nrm_texto_completo. aspx?param1=NRTC\&nValor1=1\&nValor2=43957\&nValor3=86104\&strTipM=TC.

Sala Constitucional de la Corte Suprema de Justicia. (2002). Voto 08587-2002 del 4 de septiembre de 2002. Recuperado de: de https://vlex.co.cr/vid/-498489006

N. 11640-2003 en SINALEVI- PODER JUDICIAL. (s.f.). Recuperado de: http://jurisprudencia. poderjudicial.go.cr/SCIJ_PJ/busqueda/jurisprudencia/jur_Documento.aspx?param1=Detalle_Sentencia\&param2=5\&nValor1=1\&nValor2=255857\&nValor3=53646\&tem $1=$ Asociaci\%C3\%B3n\%20cooperativa\&strTipM=E1\&|Resultado=45\&strTem=ReTem

Superintendencia de Pensiones. (2016). GOBIERNO CORPORATIVO (2016). Recuperado de: 2018. https://www.sugef.fi.cr/normativa/normativa_vigente/documentos/SUGEF\%2016-16\%20 (v_02\%20\%20diciembre\%202016).pdf

Superintendencia de Entidades Financieras. (2016). ACUERDO SUGEF 16-16. Reglamento de gobierno corporativo. La Gaceta, 235. 